\title{
Down-regulation of the PI3K/Akt signaling pathway and induction of apoptosis in CA46 Burkitt lymphoma cells by baicalin
}

\author{
Yi Huang ${ }^{1,2}$, Jianda $\mathrm{Hu}^{1 *}$, Jing Zheng ${ }^{1}$, Jing $\mathrm{Li}^{1}$, Tiannan Wei ${ }^{1}$, Zhihong Zheng ${ }^{1}$ and Yingyu Chen ${ }^{1}$
}

\begin{abstract}
Background: Baicalin, a flavone present in Scutellaria baicalensis Georgi, inhibits the growth of human leukemia and myeloma cells through induction of apoptosis.

Methods: The present study was undertaken to ascertain whether cultured Burkitt lymphoma cells undergo apoptosis when treated with baicalin. Growth rates were measured using MTT and colony formation assays, and induction of apoptosis was quantified using Annexin V and DNA fragmentation assays. Mechanisms underlying observed growth suppression were examined using Western blotting.

Results: Treatment of CA46 Burkitt lymphoma cells with baicalin for $48 \mathrm{~h}$ markedly decreased the rate of cell proliferation; an IC $\mathrm{C}_{50}$ value of $10 \mu \mathrm{M}$ was obtained. Colony formation was almost fully suppressed at $10 \mu \mathrm{M}$ baicalin. CA46 cells underwent apoptosis in response to baicalin treatment as evidenced by an increase in the percentage of cells stainable with Annexin $\mathrm{V}$, by increased DNA fragmentation, and by activation of the intrinsic (mitochondrial) pathway for cell death as characterized by increased expression of the cleaved forms of caspase-9, caspase-3, and poly (ADP-ribose) polymerase. Additionally, baicalin was found to down-regulate anti-apoptotic and up-regulate apoptotic components of the phosphatidylinositide-3-kinase (PI3K)/serine/threonine kinase (Akt) signaling pathway.

Conclusions: The concentrations at which baicalin altered expression of components of the PI3K/Akt pathway in CA46 cells were comparable to those that suppressed growth and induced apoptosis, supporting the hypothesis that the observed growth-inhibitory and apoptosis-inducing actions of baicalin in these cells are mediated by down-regulation of this pathway.
\end{abstract}

Keywords: Apoptosis, Intrinsic pathway, Baicalin, Burkitt lymphoma, CA46 cells, PI3K/Akt signaling pathway

\section{Introduction}

Burkitt lymphoma is a high-grade, rapidly-growing and aggressive B-cell non-Hodgkin's lymphoma [1]. Three forms are recognized: those endemic to Africa, sporadic forms, and those associated with immunodeficiency states. In the endemic and sporadic forms, B lymphocytes possess rearranged immunoglobulin genes and most commonly carry the $(8 ; 14)$ chromosomal translocation of the proto-oncogene $c-m y c$ [1]. Although Burkitt

\footnotetext{
* Correspondence: jdhu@medmail.com.cn

'Fujian Institute of Hematology, Fujian Provincial Key Laboratory of Hematology, Fujian Medical University Union Hospital, 29 Xinquan Road, Fuzhou, 350000, Fujian, China

Full list of author information is available at the end of the article
}

lymphoma is sensitive to chemotherapy, the different regimens used to treat this cancer are associated with varied success rates [1,2]. Prognosis depends on the stage of the disease at diagnosis and is generally worse for children, adolescents, and patients with co-existent AIDS.

Baicalin is one of several pharmacologically-active flavones present in Scutellaria baicalensis Georgi (Huangqin or Chinese skullcap), a plant widely used in traditional Chinese herbal medicine [3]. Although baicalin is generally non-toxic to normal tissues, it exhibits strong anti-inflammatory, anti-viral, and anti-tumor activities [4,5]. Growth of human leukemia and myeloma cells and of human hepatic, prostate, breast, lung, bladder, and estrogenic cancer cells is potently suppressed 
by this flavone. Molecular mechanisms underlying these growth-suppressive effects are thought to include changes in oxidation/reduction status, cell cycle inhibition, and induction of apoptosis [3-5]. Baicalininduced apoptosis in human leukemia cell lines is mediated by production of reactive oxygen species, induction of growth arrest and DNA damage-inducible protein 153 (GADD153), decreased expression of the anti-apoptotic protein $\mathrm{Bcl}-2$, activation of the intrinsic (mitochondrial) apoptotic pathway, DNA fragmentation, and cycle arrest at the G0/G1 boundary [6,7]. Treatment of doxorubicin-resistant human myeloid leukemia cells with baicalin results in decreased expression of $\mathrm{Bcl}-2$, c-myc, procaspase-3, and poly(ADPribose) polymerase (PARP), increased expression of Bad and cleaved PARP, and enhanced sensitivity to doxorubicin [8]. The growth of certain types of cultured lymphoma cells has been found to be suppressed by treatment with Scutellaria baicalensis extracts containing $21 \%$ baicalin [9]. However, no studies that examine the effects of baicalin on lymphoma cell proliferation have been reported.

The phosphatidylinositol-3-kinase (PI3K)/serine/threonine kinase (Akt) signaling pathway is essential to the survival and proliferation of human cells, and constitutive activation of this pathway is thought to play a critical role in the progression of human hematologic malignancies $[10,11]$. Inhibitors of this pathway have been shown to induce apoptosis in isolated leukemia, lymphoma, and myeloma cells. The CA46 lymphoma cell line [12], which was derived from the ascites fluid of a patient with American-type Burkitt lymphoma, carries the $(8 ; 14)$ translocation, overexpresses $B c l-2$ and $c$-myc mRNAs, and has been proven a useful model of Burkitt lymphoma. The following study was undertaken to ascertain whether baicalin down-regulates the PI3K/Akt signaling pathway in CA46 cells concurrently with induction of apoptotic cell death.

\section{Materials and methods Materials}

Baicalin $\left(\mathrm{C}_{21} \mathrm{H}_{18} \mathrm{O}_{11}, \mathrm{MW}\right.$ 446.35) was purchased from Qingzhe (Nanjing, Jiangsu, China). A $50 \mathrm{mM}$ stock solution was prepared by dissolving $22.3 \mathrm{mg}$ of the drug in $1 \mathrm{ml}$ of dimethyl sulfoxide (DMSO; Sigma, St. Louis, $\mathrm{MO}$, USA). The stock solution was maintained at $-20^{\circ} \mathrm{C}$ and was diluted to appropriate concentrations with culture medium immediately before experimental use. Under these conditions, no baicalin solubility issues were encountered. The highest final concentration of DMSO in baicalin-treated preparations was $0.08 \%$; the viability of control preparations was unaffected at this DMSO concentration.

\section{Cell culture}

The Jurkat, K562, HL-60, and CA46 Burkitt lymphoma cell lines were obtained from the China Center for Type Culture Collection (CCTCC; Wuhan, Hubei, China). Cultures were maintained in RPMI-1640 medium (Gibco, Grand Island, NY, USA) with 10\% fetal bovine serum (FBS; Gibco, Grand Island, NY, USA) at $37^{\circ} \mathrm{C}$ in a humidified atmosphere containing $5 \% \mathrm{CO}_{2}$.

\section{Proliferation assay}

The 3-(4,5-dimethylthiazol-2-yl)-2,5 diphenyltetrazolium bromide (MTT) assay was used to measure the rate of cell proliferation. Briefly, CA46 cells $\left(1 \times 10^{4} /\right.$ well $)$ were seeded in 96-well plates and treated with baicalin at varying concentrations. After varying incubation times, cells were treated with $20 \mu \mathrm{l}$ of MTT solution (Sigma, St. Louis, MO, USA) at a final concentration of $5 \mathrm{mg} / \mathrm{ml}$ for $4 \mathrm{~h}$ at $37^{\circ} \mathrm{C}$. Medium was then removed, DMSO $(200 \mu \mathrm{l})$ was added, and the absorbance maxima at test and reference wavelengths of 490 and $630 \mathrm{~nm}$, respectively, were recorded. The proliferation inhibitory rate (\%) was calculated as: [1-(absorbance of baicalin treated group/ absorbance of control group) $] \times 100$.

\section{Colony-forming assay}

CA46 cells were seeded at a density of $4 \times 10^{2} /$ well in 24-well flat bottom plates and then cultured with baicalin at different concentrations in RPMI-1640 medium with $10 \%$ FBS and $0.7 \%$ methylcellulose at $37^{\circ} \mathrm{C}$ for 10 days. Colony formation was observed using phase contrast inverse microscopy. The resulting cell colonies ( $>50$ cells/colony) were counted, and colony formation rate (\%) was calculated as: (formed colonies/seeded cells) $\times 100$.

\section{Measurements of cells in early and late apoptosis}

The ability of baicalin to induce apoptosis in CA46 cells was examined by Annexin V-FITC/PI double-staining and flow cytometry. Preparations were treated with baicalin at varying concentrations for $48 \mathrm{~h}$. Cells were then harvested, resuspended to $5 \times 10^{5} / \mathrm{ml}$ in binding buffer (HEPES, $10 \mathrm{mM}, \mathrm{pH} 7.4,150 \mathrm{mM} \mathrm{NaCl}, 5 \mathrm{mM} \mathrm{KCl}, 1 \mathrm{mM} \mathrm{MgCl}$, $1.8 \mathrm{mM} \mathrm{CaCl} 2$ ), and doubly stained with Annexin V-Fluorescein Isothiocyanate (FITC)/Propidium Iodide (PI) (BD, Franklin, NJ, USA) according to the manufacturer's instructions. The percentages of viable, early apoptotic, late apoptotic, and necrotic cells were determined using a CPICX XL flow cytometer (Beckman Coulter, Fullerton, CA, USA).

\section{DNA fragmentation assay}

After $48 \mathrm{~h}$ exposure to baicalin at varying concentrations, CA46 cells were collected by centrifugation and washed twice with PBS. Cell pellets were resuspended in 
$40 \mu \mathrm{l}$ of lysis buffer (0.1 M EDTA, $0.1 \mathrm{M}$ Tris-HCl pH 8.0, $0.8 \% \mathrm{SDS}$ ) and subsequently treated with $10 \mu \mathrm{l}$ RNase A $(50 \mu \mathrm{g} / \mathrm{ml})$ at $37^{\circ} \mathrm{C}$ for $1 \mathrm{~h}$ and with $10 \mu \mathrm{l}$ proteinase $\mathrm{K}(20 \mu \mathrm{g} / \mathrm{ml})$ at $50^{\circ} \mathrm{C}$ overnight. Extracted cellular DNA was subjected to agarose gel (2.0\%) chromatography at $35 \mathrm{~V}$ for $3 \mathrm{~h}$. Gels were photographed after staining with $0.5 \mu \mathrm{g} / \mathrm{ml}$ ethidium bromide.

\section{Western blot analyses}

Western blotting was performed as described previously [8]. CA46 cells were treated with $40 \mu \mathrm{M}$ baicalin for $0-72 \mathrm{~h}$ prior to lysis. Protein Detector LumiGLO Western Blot Kits were purchased from KPL (Gaithersburg, MD, USA). Antibodies to the following proteins were used for these analyses: $\beta$-actin (NeoMarkers, Fremont, CA, USA); Akt, p-Akt (Ser473), mammalian target of rapamycin (mTOR), p-mTOR (Ser2448), IкB, p-IкB (Ser 32), PARP, cleaved caspase-9 (Asp330), and cleaved caspase-3 (Asp175) (Cell Signaling, Danvers, MA, USA); NF-кB p65 (eBioscience, San Diego, CA, USA). The density of $\beta$-actin served as an internal loading control.

\section{Statistical analysis}

Experimental findings are expressed as means \pm standard deviation. Comparisons involving different baicalin concentrations or incubation times were conducted using analysis of variance (ANOVA). Multiple comparisons were performed using the Bonferroni procedure with type-I error adjustment when significance was obtained. The level of significance was set at 0.05 . Statistical analyses were performed using SAS 9.1 statistical software (SAS Institute Inc., Cary, NC, USA).

\section{Results}

\section{Inhibition of cell proliferation and colony formation}

Baicalin inhibited the proliferation of CA46 cells in a concentration- and time-dependent manner, with almost complete inhibition observed at 48-96 h of treatment with $20-40 \mu \mathrm{M}$ drug (Figure $1 \mathrm{~A}$ ). An $\mathrm{IC}_{50}$ of $10 \mu \mathrm{M}$ was obtained (Figure 1B). After $48 \mathrm{~h}$ of treatment, rates of proliferation declined in a baicalin concentrationdependent manner, with $15.5 \pm 4.7 \%$ and $89.4 \pm 2.8 \%$ inhibitions observed at 5 and $40 \mu \mathrm{M}$ drug, respectively. Baicalin also suppressed formation of colonies of CA46 cells at 10 days post-seeding (Figures $2 \mathrm{~A}$ and $2 \mathrm{~B}$ ). Control preparations formed colonies at a rate of $36.2 \pm 4.0 \%$. In contrast, rates of colony formation for preparations treated with baicalin at 5 and $10 \mu \mathrm{M}$ were $14.0 \pm 2.3 \%$ and $0.5 \pm 0.5 \%$, respectively $(P<0.01)$.

\section{Induction of apoptosis}

The percentage of CA46 cells undergoing apoptotic cell death was increased by baicalin in a concentrationdependent manner (Figure 3A-D). The percentages of all cells in apoptosis, as determined by the sum of cells in early and late apoptosis, at various baicalin concentrations are presented in Figure 3E. After $48 \mathrm{~h}$ of treatment, $15.2 \pm 1.6 \%$ of cells were apoptotic at $10 \mu \mathrm{M}$ baicalin and $35.4 \pm 2.6 \%$ of cells were apoptotic at $40 \mu \mathrm{M}$ baicalin. When the ability of baicalin to induce DNA fragmentation, a hallmark of apoptosis, was examined after $48 \mathrm{~h}$ of culture (Figure 3F), no significant fragmentation was observed in preparations treated with solvent or $5 \mu \mathrm{M}$ baicalin. However, fragmentation was clearly observable in preparations treated with 20 and $40 \mu \mathrm{M}$ baicalin.

\section{Suppression of the PI3K/Akt pathway}

The possibility that the induction of apoptosis in CA46 cells by baicalin involved suppression of Akt signaling was explored. Basal expression of p-Akt (the activated form of Akt) was examined in C46 cells, in three leukemic cell types, and in normal peripheral blood mononuclear cells under untreated conditions. As compared to normal peripheral blood mononuclear cells, high degrees of p-Akt expression were observed in C46 lymphoma cells and in all types of leukemic cells (Figure 4A). The effects of baicalin on expression of Akt and of specific downstream components of the Akt pathway in CA46 cells were then examined. Expression of the following components in their various forms was measured: (a) Akt (inactive) and p-Akt; (b) the transcription

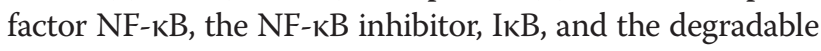
form of IкB, p-IкB; (c) the cell cycle regulatory kinase mTOR (inactive) and p-mTOR, the phosphorylated and active form of the kinase. An increase in the dephosphorylated form of Akt was observed at $24 \mathrm{~h}$ of baicalin treatment, and an increase in the dephosphorylated form of mTOR was observed at $48 \mathrm{~h}$ of baicalin treatment. Dramatic reductions in expression of NF- $k B$ and $\mathrm{p}-\mathrm{I} \kappa \mathrm{B}$ were observed in response to baicalin; these reductions were time-dependent. By contrast, expression of IKB increased with time of baicalin treatment (Figure 4B). Changes in expression of these components were quantified, and the findings are summarized in Figure 4C.

The profound decreases in expression of total cellular NF-kB and p-IkB, accompanied by significant increases in $\mathrm{IkB}$ expression, in response to baicalin treatment were interpreted to indicate a condition wherein nuclear NF$\mathrm{kB}$ signaling should be dramatically impaired. Accordingly, expression of nuclear NF-kB was reduced by $25.8 \%, 50.4 \%$ and $65.4 \%$ at 24,48 and $72 \mathrm{~h}$ of treatment with $40 \mu \mathrm{M}$ baicalin, respectively (not shown).

\section{Activation of the intrinsic mitochondrial apoptotic pathway}

It was considered essential to ascertain whether baicalin suppresses proliferation of CA46 cells and promotes DNA fragmentation in these cells through activation of 

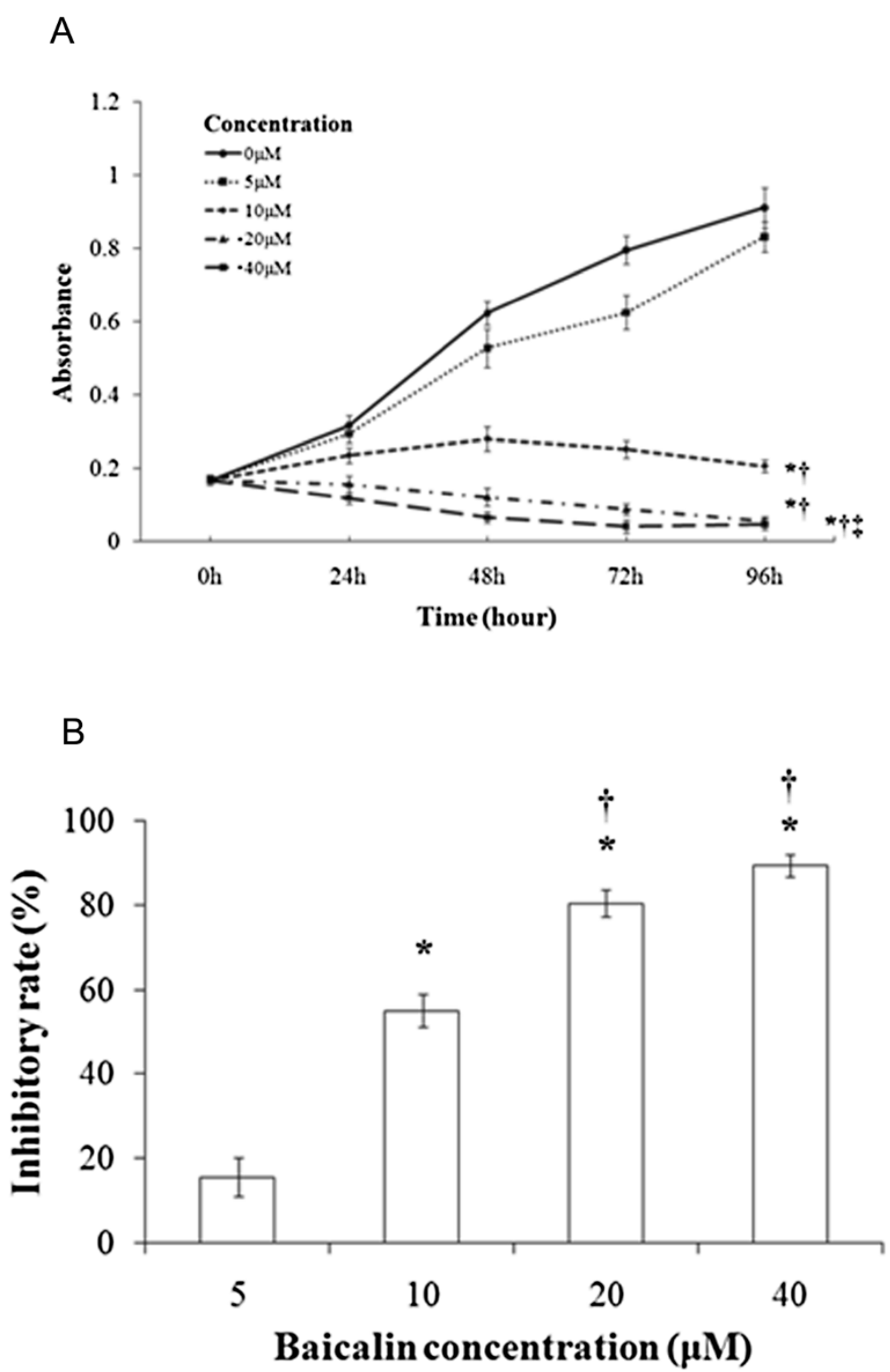

Figure 1 Proliferation of CA46 cells in the absence and presence of baicalin. Cells were seeded at a density of $1 \times 10^{4} /$ well and treated with baicalin at the concentrations and for the times indicated. Cytotoxicity was determined according to the MTT assay. Sampling was performed in triplicate for each experimental condition, and findings are expressed as means \pm standard deviation for three independent experiments. (A) Proliferation as a function of incubation time and baicalin concentration. Absorbance maxima are provided on the ordinate. (B) Rates of proliferation as a function of baicalin concentration. Cells were treated for $48 \mathrm{~h}$ with baicalin at the concentrations indicated. Proliferation rates were determined as described in Materials and methods. ${ }^{*} P<0.01$ compared to the solvent control; ${ }^{\dagger} P<0.01$ compared to $5 \mu \mathrm{M}$ baicalin; $\$ P<0.01$ compared to $10 \mu \mathrm{M}$ baicalin.

the intrinsic (mitochondrial) apoptotic pathway. To this end, expression of relevant apoptosis-related proteins was examined by Western blotting. Treatment with baicalin increased expression of the pro-apoptotic proteins Bax, activated (cleaved) caspase 3, activated (cleaved) caspase 9, and activated (cleaved) PARP. By contrast, expression of the anti-apoptotic protein $\mathrm{Bcl}-2$ and of the inactive form of PARP was decreased following treatment with the drug (Figure 4D). Relative expression of these proteins after baicalin treatment was quantified, and findings are presented in Figure 4E. The concentrations at which baicalin altered expression of these apoptosisrelated proteins were similar to those at which cell proliferation was suppressed and expression of components of the PI3K/Akt signaling pathway was altered, supporting the hypothesis that the growth-inhibitory and apoptosis- 


\section{A}

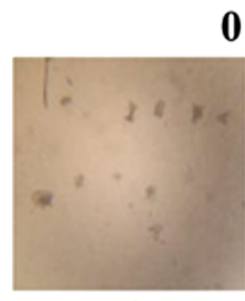

$40 \times$

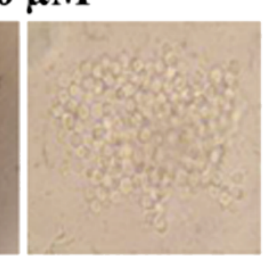

$400 \times$

$5 \mu \mathrm{M}$

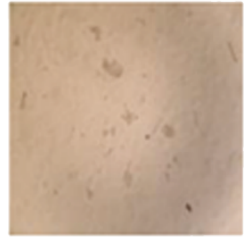

$40 \times$

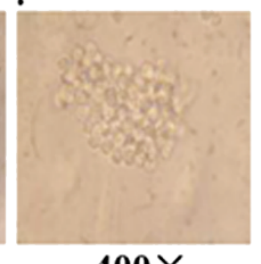

$400 \times$

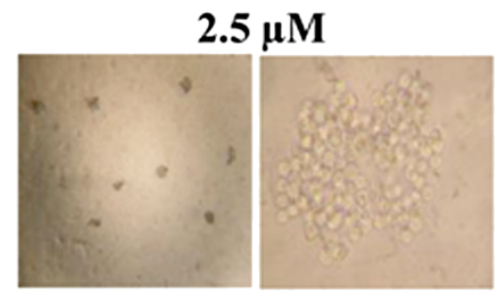

$40 \times$

$400 \times$

$10 \mu \mathrm{M}$

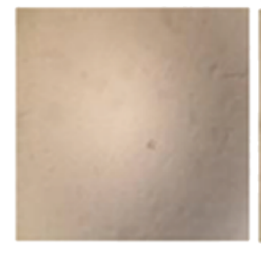

$40 \times$

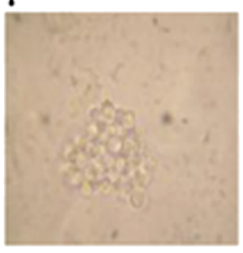

$400 \times$

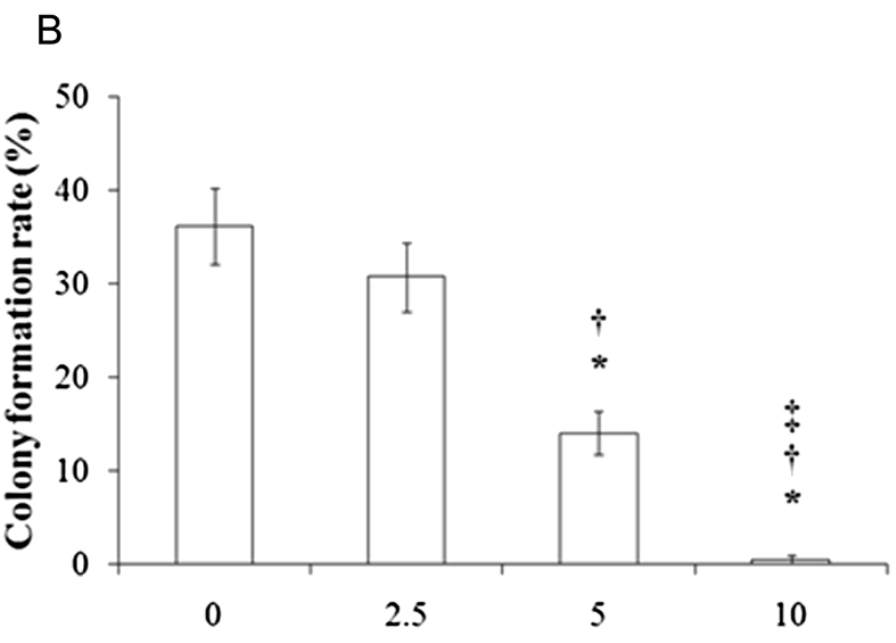

Baicalin concentration $(\mu \mathrm{M})$

Figure 2 Formation of CA46 cell colonies after treatment with baicalin at varying concentrations. Cells $\left(4 \times 10^{2} /\right.$ well) were cultured with baicalin at the indicated concentrations for 10 days. Colony formation rates were determined as described in Materials and methods. Sampling was performed in triplicate for each experimental condition. (A), phase contrast inverse microscopy. (B), colony formation rates with findings presented as means \pm standard deviation for three independent experiments. ${ }^{*} P<0.01$ compared to the solvent control; ${ }^{\dagger} P<0.01$ compared to $2.5 \mu \mathrm{M}$ baicalin; ${ }^{\ddagger} P<0.01$ compared to $5 \mu \mathrm{M}$ baicalin.

inducing actions of baicalin in CA46 cells are mediated by suppression of PI3K/Akt signaling pathway.

\section{Discussion}

The present study is the first to demonstrate that baicalin is toxic to Burkitt lymphoma cells in culture. Treatment with this flavone at $10 \mu \mathrm{M}$ concentrations resulted in a marked decrease in the rate of proliferation of cultured CA46 cells and in the rate at which these cells formed colonies. Baicalin treatment caused CA46 cells to undergo apoptosis as evidenced by an increase in the percentage of Annexin V-stainable cells and by increased DNA fragmentation. Baicalin also activated the mitochondrial pathway for cell death, as shown by increased expression of activated caspase-9, activated caspase-3, and cleaved PARP. Treatment of CA46 cells with baicalin was found to suppress components of the PI3K/Akt signaling pathway, as shown by decreased expression of p-Akt, mTOR, p-mTOR, NF-kB, and p-IкB. These decreases were observed concurrently with increased expression of non-phosphorylated IкB. The concentrations at which baicalin altered the expression of components of the PI3K/Akt signaling pathway were similar to those 

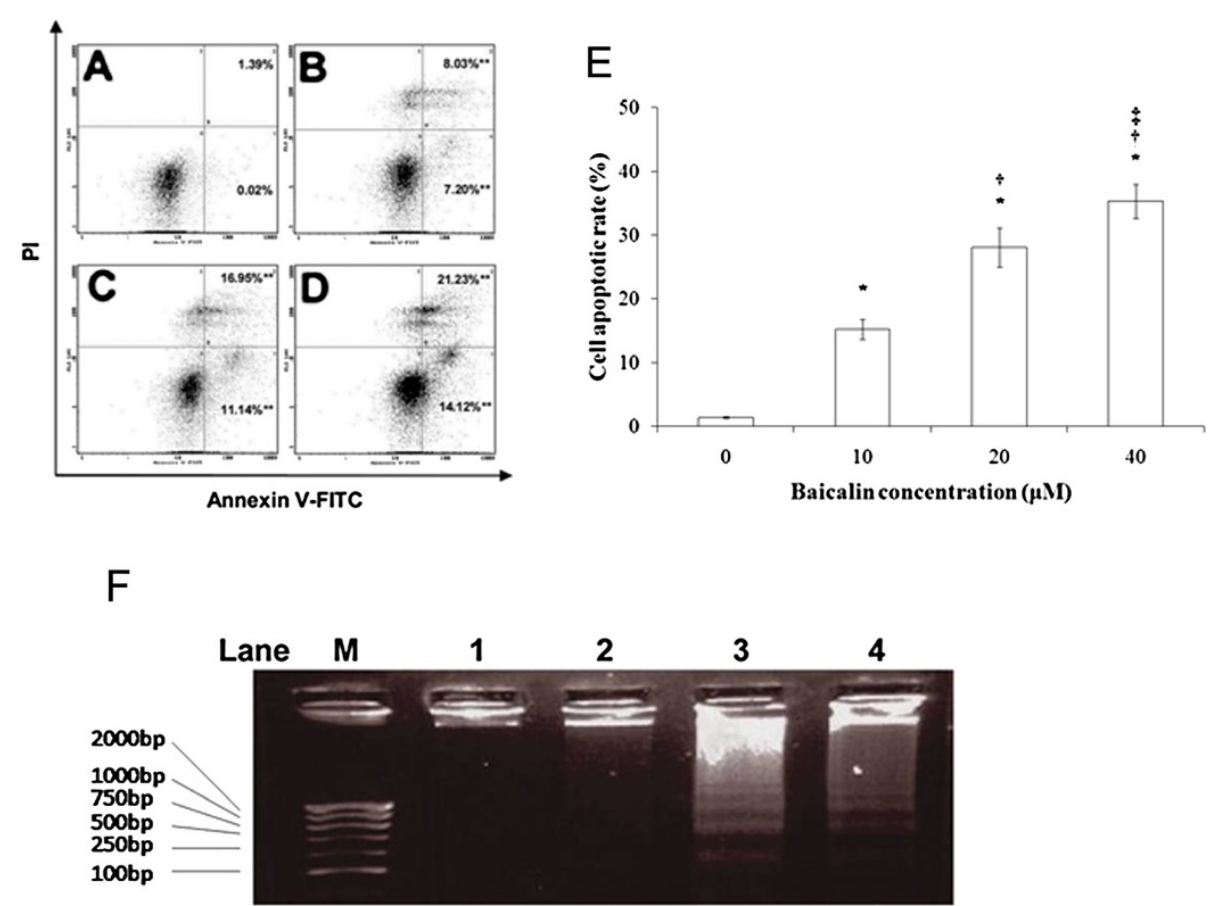

Figure 3 Induction of apoptosis in CA46 cells by baicalin. Annexin V-FITC/PI double staining and flow cytometry were used to determine the percentages of cells in apoptosis. Viable, early apoptotic, late apoptotic, and necrotic cells were determined after $48 \mathrm{~h}$ treatments with baicalin at varying concentrations. Cells were treated with baicalin at (A) 0 , (B) 10, (C) 20, and (D) $40 \mu$ M. Bottom left quadrants, viable cells; bottom right quadrants, early apoptotic cells; top right quadrants, late apoptotic cells; top left quadrants, necrotic cells. (E) Percentages of cells in apoptosis at each baicalin concentration. Cells in the bottom right and top right quadrants were summed to obtain the percentage of all cells in apoptosis. Findings are presented as the means of three similar experiments \pm standard deviation. (F) CA46 cells were treated for $48 \mathrm{~h}$ with baicalin at 0 (lane 1), 10 (lane 2), 20 (lane 3), and 40 (lane 4) $\mu \mathrm{M}$. Cellular DNA was extracted and subjected to agarose gel electrophoresis as described in Materials and methods. Gels were stained with ethidium bromide and photographed. Lane M presents migration of D2000-Markers (100, 250, $500,750,1000,2000$ bp). Findings are representative of those obtained on three separate occasions. ${ }^{*} P<0.05$ compared to the solvent control; ${ }^{\dagger} P<0.05$ compared to $10 \mu \mathrm{M}$ baicalin; ${ }^{\ddagger} P<0.05$ compared to $20 \mu \mathrm{M}$ baicalin.

at which the drug suppressed growth and induced apoptosis, supporting the hypothesis that the growth-inhibitory and apoptosis-inducing actions of baicalin in CA46 cells are mediated by suppression of this pathway.

Although baicalin has been found to induce apoptosis in several malignant hematologic cell types, the mechanism responsible for the induction has not been examined in detail. Baicalin treatment has been shown to promote activation of the mitochondrial pathway of apoptosis and to induce DNA fragmentation and cycle arrest in human leukemia cells but the upstream mechanisms responsible for these actions were not examined [6-8]. Baicalein, a non-glycosylated derivative of baicalin and one of the major flavones present in Scutellaria baicalensis Georgi, was recently reported to induce apoptosis in human myeloma cells through inhibition of Akt activation [13]. However, baicalein and baicalin are not identical in their cellular actions. Although both flavones induce apoptosis in several types of murine and human cancer cells, events mediating growth suppression by baicalein do not routinely duplicate those mediated by baicalin [14-19]. In addition, baicalin is unable to duplicate the baicalein-induced activation of the IL-6mediated signaling cascade seen in human myeloma cells [13]. Whether baicalein is similar to baicalin in its action on Akt and downstream mediators in Burkitt lymphoma cells remains to be demonstrated.

The PI3K/Akt growth signaling pathway is comprised of a family of intracellular protein kinases, each of which is regulated by phosphorylation and possesses unique substrate specificity. Activated Akt, the primary mediator of PI3K-initiated signaling, supports survival of various hematologic malignancies through its ability to phosphorylate and activate a wide variety of downstream targets $[10,20,21]$. In the present study, inhibition of Akt phosphorylation, rather than down-regulation of Akt expression, was observed during treatment of CA46 cells with baicalin. Since Akt is an early player in the PI3K/ Akt signaling pathway, it is conceivable that the growthsuppressive effects of baicalin in CA46 cells are attributable to an interaction of the drug with the kinase. In support of this hypothesis, selective inactivation of Akt in Jurkat $\mathrm{T}$ lymphoblastic leukemia cells causes these cells to undergo apoptotic death via the mitochondrial 


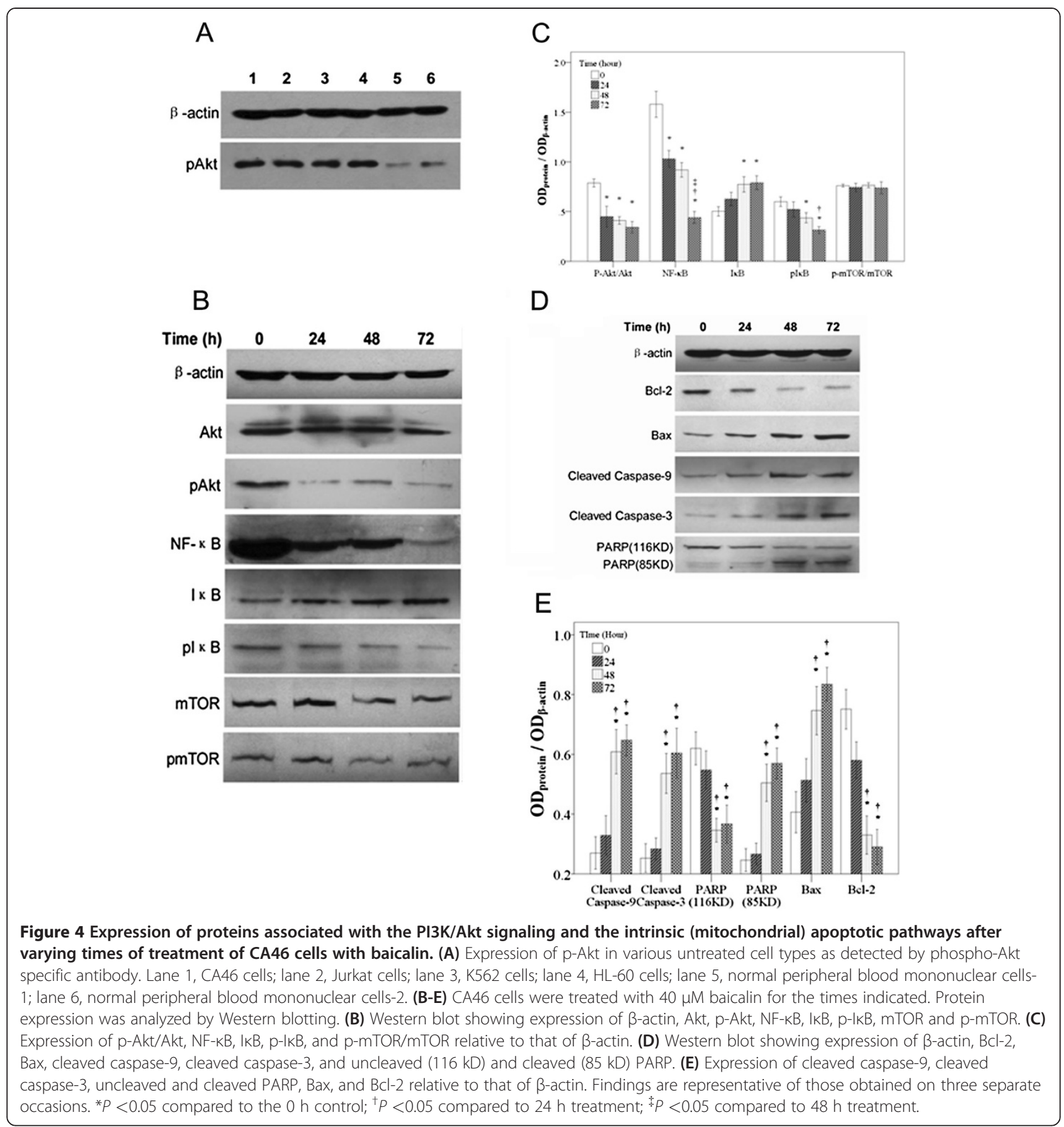

pathway [22]. Because PI3K expression/activity was not measured in the present study, the involvement of this kinase in the observed effects of baicalin remains unclear. Future studies with various lymphoma cells lines are planned to explore the possibility that PI3K is targeted by baicalin.

NF-kB and mTOR, downstream components of the PI3K/Akt pathway, are thought to function importantly in maintenance of hematologic malignancies [10,11,20,2325]. The transcription factor $\mathrm{NF}-\mathrm{kB}$ is inactivated when complexed with IkB in the cytosol. Phosphorylation of $\mathrm{I} \kappa \mathrm{B}$ renders it a substrate for degradation, resulting in translocation of free NF- $\mathrm{BB}$ to the nucleus and transcriptional activation of anti-apoptotic genes. Activated Akt indirectly signals ІкB phosphorylation, thereby promoting transcription of anti-apoptotic genes, whereas inactivation of Akt promotes apoptosis. mTOR is directly phosphorylated by activated Akt. Phosphorylated mTOR, the active form of the kinase, promotes cell cycle transition from the G1 to $\mathrm{S}$ phase via phosphorylation of its 
two downstream targets, p70 S6 kinase and eukaryotic initiation factor $4 \mathrm{E}$-binding protein 1 . These phosphorylations favor translation of mRNAs for certain growth-promoting proteins such as cyclin D and c-myc. Accordingly, pharmacologic antagonists of mTOR are anticipated to be effective against many types of solid tumors and hematologic cancers $[10,11,25]$. In the present study, expression of NF-kB, $\mathrm{p}$-IkB, mTOR, and p-mTOR was found to be downregulated in baicalin-treated CA46 cells. These findings support the hypothesis that induction of apoptosis in CA46 cells by baicalin is mediated by the suppression of PI3K/Akt/NF-kB and PI3K/Akt/mTOR signaling.

Suppression of Akt in cancer cells is associated with activation of the mitochondrial apoptotic pathway involving the caspase-9-dependent caspase cascade $[20,24]$. Treatment of CA46 cells with baicalin was found to increase the level of cleaved caspase- 9 concurrently with a decrease in procaspase- 9 protein, to increase level of cleaved caspase- 3 concurrently with a decrease in procaspase- 3 protein, to increase expression of cleaved PARP concurrently with decreased expression of uncleaved PARP, and to promote DNA degradation. These findings support the proposal that apoptotic death in baicalin-treated CA46 cells is mediated by the following events in sequence: cleavage of procaspase-9, cleavage of procaspase-3, cleavage of PARP, and degradation of DNA.

Based on the findings presented in this report, it is suggested that baicalin induces apoptosis in CA46 Burkitt lymphoma cells through down-regulation of the PI3K/Akt signaling pathway and activation of the mitochondrial death pathway. The findings described in this report warrant further investigations of the efficacy of baicalin against this form of lymphoma.

\section{Support and Financial Disclosure Declaration}

This work was supported by grants from National Science \& Technology Pillar Program (2008BAl61B01), the Fujian Bureau of Education (NCEFJ-0604), the Fujian Bureau of Public Health (2001-CX-02), and Fujian Medical University (JS06081).

\section{Competing interests}

The authors declare that they have no competing interests.

\section{Author details}

${ }^{1}$ Fujian Institute of Hematology, Fujian Provincial Key Laboratory of Hematology, Fujian Medical University Union Hospital, 29 Xinquan Road, Fuzhou, 350000, Fujian, China. ${ }^{2}$ Provincial Clinical College of Fujian Medical University, 134 Dong Street, Fuzhou, 350000, Fujian, China.

\section{Authors' contributions}

YH: guarantor of integrity of the entire study, study concepts, study design, definition of intellectual content, literature research, experimental studies, data acquisition, data analysis, statistical analysis, manuscript preparation, manuscript editing, manuscript review, JH: guarantor of integrity of the entire study, study concepts, study design, definition of intellectual content, literature research, manuscript editing, manuscript review, JZ: experimental studies, data acquisition, JL: experimental studies, data acquisition, TW: data analysis, ZZ: statistical analysis, YC: manuscript preparation. All authors read and approved the final manuscript.

Received: 27 March 2012 Accepted: 20 May 2012

Published: 20 May 2012

\section{References}

1. God JM, Haque A: Burkitt lymphoma: pathogenesis and immune evasion. J Oncol 2010, pii: 516047. Epub 2010 Oct 5. PMID: 20953370.

2. Okebe JU, Skoetz N, Meremikwu MM, Richards S: Therapeutic interventions for Burkitt lymphoma in children. Cochrane Database Syst Rev 2011, 6(7): CD005198.

3. Li C, Lin G, Zuo Z: Pharmacological effects and pharmacokinetics properties of Radix Scutellariae and its bioactive flavones. Biopharm Drug Dispos 2011, doi: 10.1002/bdd.771. [Epub ahead of print].

4. Li-Weber M: New therapeutic aspects of flavones: The anticancer properties of Scutellaria and its main active constituents Wogonin, Baicalein and Baicalin. Cancer Treat Rev 2009, 35:57-68.

5. Srinivas NR: Baicalin, an emerging multi-therapeutic agent: pharmacodynamics, pharmacokinetics, and considerations from drug development perspectives. Xenobiotica 2010, 40:357.

6. Shieh DE, Cheng HY, Yen MH, Chiang LC, Lin CC: Baicalin-induced apoptosis is mediated by Bcl-2-dependent, but not p53-dependent, pathway in human leukemia cell lines. Am J Chin Med 2006, 34:245-261.

7. Lu HF, Hsueh SC, Ho YT, Kao MC, Yang JS, Chiu TH, Huamg SY, Lin CC, Chung JG: ROS mediates baicalin-induced apoptosis in human promyelotic leukemia $\mathrm{HL}-60$ cells through the expression of the Gadd153 and mitochondrial-dependent pathway. Anticancer Res 2007, 27:117-126.

8. Zheng J, Hu JD, Huang Y, Chen BY: Effects of baicalin on proliferation and apoptosis of adriamycin-resistant human leukemia HL-60/ADR cells. Zhongguo Shi Yan Xue Ye Xue Za Zhi 2009, 17:1198-1202.

9. Kumagai T, Müller Cl, Desmond JC, Imai Y, Heber D, Koeffler HP: Scutellaria baicalensis, a herbal medicine: Anti-proliferative and apoptotic activity against acute lymphocytic leukemia, lymphoma and myeloma cell lines. Leuk Res 2007, 31:523-530.

10. Kawauchi K, Ogasawara T, Yasuyama M, Otsuka K, Yamada O: The PI3K/Akt pathway as a target in the treatment of hematologic malignancies. Anticancer Agents Med Chem 2009, 9:550-559.

11. Vu C, Fruman DA: Target of rapamycin signaling in leukemia and lymphoma. Clin Cancer Res 2010, 16:5374-5380.

12. Magrath IT, Freeman CB, Pizzo P, Gadek J, Jaffe E, Santaella M, Hammer C, Frank M, Reaman G, Novikovs L: Characterization of lymphoma-derived cell lines: comparison of cell lines positive and negative for EpsteinBarr virus nuclear antigen. II. Surface markers. J Natl Cancer Inst 1980, 64:477-483.

13. Liu S, Ma Z, Cai H, Qian L, Rong W, Kawano M: Inhibitory effect of baicalein on IL-6-mediated cascades in human myeloma cells. Eur $J$ Hematol 2009, 84:137-144.

14. Chang WH, Chen CH, Lu FJ: Different effects of baicalein, baicalin and wogonin on mitochondrial function, glutathione content and cell cycle progression in human hepatoma cell lines. Planta Med 2002, 68:128-132.

15. Ciesielska E, Gwardys A, Metodiewa D: Anticancer, antiradical and antioxidative actions of novel Antoksyd $\mathrm{S}$ and its major components, baicalin and baicalein. Anticancer Res 2002, 22:2885-2891.

16. Ma Z, Otsuyama K, Liu S, Abroun S, Ishikawa H, Tsuyama N, Obata M, Li FJ, Zheng X, Maki Y, Miyamoto K, Kawano MM: Baicalein, a component of Scutellaria radix from Huang-Lian-Jie-Du-Tang (HLDT), leads to suppression of proliferation and induction of apoptosis in human myeloma cells. Blood 2005, 105:3312-3318.

17. Chen YC, Chow JM, Lin CW, Wu CY, Shen SC: Baicalein inhibition of oxidative-stress-induced apoptosis via modulation of ERKs activation and induction of HO-1 gene expression in rat glioma cells C6. Toxicol Appl Pharmacol 2006, 216:263-273.

18. Lin HY, Shen SC, Lin CW, Yang LY, Chen YC: Baicalein inhibition of hydrogen peroxide-induced apoptosis via ROS-dependent heme oxygenase 1 gene expression. Biochim Biophys Acta 2007, 1773:1073-1086.

19. Zhou QM, Wang S, Zhang H, Lu YY, Wang XF, Motoo Y, Su SB: The combination of baicalin and baicalein enhances apoptosis via the ERK/p38 MAPK pathway in human breast cancer cells. Acta Pharmacol Sin 2009, 30:1648-1658 
20. Chang F, Lee JT, Navolanic PM, Steelman LS, Shelton JG, Blalock WL, Franklin RA, McCubrey JA: Involvement of PI3K/Akt pathway in cell cycle progression, apoptosis, and neoplastic transformation: a target for cancer chemotherapy. Leukemia 2003, 17:590-603.

21. Tokunaga E, Oki E, Egashira A, Sadanaga N, Morita M, Kakeji Y, Maehara Y: Deregulation of the Akt pathway in human cancer. Curr Cancer Drug Targets 2008, 8:27-36.

22. Uriarte SM, Joshi-Barve $S$, Song Z, Sahoo R, Gobejishvili L, Jala VR, Haribabu B, McClain C, Barve S: Akt inhibition upregulates FasL, downregulates c-FLIPs and induces caspase-8-dependent cell death in Jurkat T lymphocytes. Cell Death Differ 2005, 12:233-242.

23. Escobar-Díaz E, López-Martín EM, Hernández Del Cerro M, Puig-Kroger A, Soto-Cerrato V, Montaner B, Giralt E, García-Marco JA, Pérez-Tomás R, GarciaPardo A: AT514, a cyclic depsipeptide from Serratia marcescens, induces apoptosis of B-chronic lymphocytic leukemia cells: interference with the Akt/NF-kappaB survival pathway. Leukemia 2005, 19:572-579.

24. Chen Y, Wang BC, Xiao Y: PI3K: A potential therapeutic target for cancer. J Cell Physiol 2011, Sep 21. doi: 10.1002/jcp.23038 [Epub ahead of print].

25. Dazert E, Hall MN: mTOR signaling in disease. Curr Opin Cell Biol 2011, Sep 29 [Epub ahead of print]

doi:10.1186/1756-9966-31-48

Cite this article as: Huang et al:: Down-regulation of the PI3K/Akt signaling pathway and induction of apoptosis in CA46 Burkitt lymphoma cells by baicalin. Journal of Experimental \& Clinical Cancer Research 2012 31:48.

\section{Submit your next manuscript to BioMed Central and take full advantage of:}

- Convenient online submission

- Thorough peer review

- No space constraints or color figure charges

- Immediate publication on acceptance

- Inclusion in PubMed, CAS, Scopus and Google Scholar

- Research which is freely available for redistribution 